Cite this: Soft Matter, 2014, 10, 931

\title{
Microarrays and single molecules: an exciting combination
}

\begin{abstract}
Stefan Howorka*ab and Jan Hesse ${ }^{b}$
Biomolecules positioned at interfaces have spawned many applications in bioanalysis, biophysics, and cell biology. This Highlight describes recent developments in the research areas of protein and DNA arrays, and single-molecule sensing. We cover the ultrasensitive scanning of conventional microarrays as well as the generation of arrays composed of individual molecules. The combination of these tools has improved the detection limits and the dynamic range of microarray analysis, helped develop powerful singlemolecule sequencing approaches, and offered biophysical examination with high throughput and molecular detail. The topic of this Highlight integrates several disciplines and is written for interested chemists, biophysicists and nanotechnologists.
\end{abstract}

Received 2nd October 2013

Accepted 9th December 2013

DOI: $10.1039 / c 3 s m 52561 a$

www.rsc.org/softmatter throughput of assays such as sequencing-by-synthesis of singulated strands. ${ }^{7}$ The known position of isolated molecules can furthermore facilitate their biophysical and structural examination without interference from other nearby molecules. ${ }^{8-12}$ Finally, patterns of single biomolecules can be exploited in cell biology as tools to mimic cell surfaces and thereby study cell adhesion and signaling processes. ${ }^{13-18}$ Hence, while the second topic overlaps with the first in the ultrasensitive read-out of arrays, it goes beyond this classical remit. Rather, it includes biophysical and cell biological studies which are of equal importance.

A concluding chapter will identify current trends in singlemolecule array analysis and potential future areas of development and research.

\section{Single-molecule readout of microarrays and advanced ultrasensitive detection techniques}

This chapter covers the sensing of microarrays with ultrasensitive methods and provides a brief survey of relevant advanced methods to detect individual protein or DNA molecules. Not all methods have yet been applied for array scanning. However, some have been used in the related context of creating single-molecule arrays. ${ }^{22}$ This indicates the dynamic and overlapping nature of research into arrays and single-molecule sensing.

In one of the first examples of the ultrasensitive readout of conventional mRNA microarrays, ${ }^{21}$ wide-field fluorescence microscopy was used. ${ }^{23}$ Scanning of microarray slides with areas of several $\mathrm{cm}^{2}$ was achieve with a new fast read-out mode. ${ }^{29} \mathrm{In}$ addition, slides with optimized microarray coatings were used to attain highly specific analyte binding and minimize unspecific binding. Under these optimized conditions, the sensitivity 
was in the femtomolar range and the dynamic range was 4.7 logs (Fig. 1). ${ }^{21}$ The high-speed scanning of slides was also applied to monitor the expression of cancer cell subpopulations ${ }^{\mathbf{2 4}}$ and to characterize the variety of DNA molecules with large genomic and tandem repeat mutations..$^{25,26}$ As a limitation, wide-field fluorescence microscopy can only detect individual molecules when they are spaced beyond the diffraction limit at low surface densities.

To resolve individual molecules at high bulk concentrations, zero-mode waveguides have been developed. ${ }^{27}$ In these analysis platforms, glass substrates are coated with $100 \mathrm{~nm}$ thin metallic masks featuring nanoscopic holes with diameters smaller than the wavelength of light. The resulting small excitation volume of a few zeptoliters helps illuminate single molecules within bulk concentrations of up to $20 \mu \mathrm{M}$. Zero-mode waveguides are used for a sequencing-by-synthesis approach which tracks the polymerase-mediated incorporation of fluorescence-labeled nucleotides present at high concentrations. ${ }^{28}$

Other routes based on conventional light microscopy can achieve nm-resolution for single molecules spaced below the diffraction limit. ${ }^{29}$ The first approach of these super-resolution methods, stimulated emission depletion (STED) microscopy, ${ }^{30}$
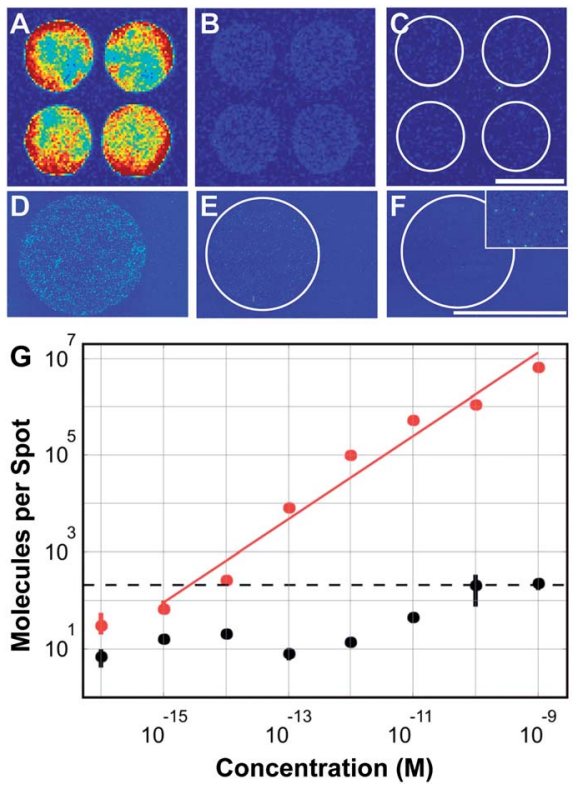

Fig. 1 Ultransensitive read-out of nucleic acid microarrays. (A-F) Fluorescence scans of DNA microarrays spotted on (A-C) commercial substrates (SuperAldehyde, Telechem Inc) and on (D-F) customcoated aldehyde-glass coverslips ${ }^{19}$ acquired using (A-C) a ScanArray 4000 reader and $(D-F)$ a single-molecule reader. ${ }^{20}$ Microarrays were hybridized with different concentrations of Cy5-labeled targetoligonucleotide: (A) 100 pM, (B) 10 pM, (C) 1 pM, (D) 100 fM, (E) 10 fM, (F) $1 \mathrm{fM}$. The inset in (F) shows single molecule signals at 5 -fold higher magnification. Scale bars: $100 \mu \mathrm{m}$. (G) Number of specifically hybridized (red) and unspecifically adsorbed (black) oligonucleotide molecules per spot vs. sample concentration. The surface density increases linearly over six orders of magnitude; unspecific binding limits the dynamic range to 4.7 logs. Assuming a minimum signal-to-noise ratio of 10 as the criterion for reliable analysis (dashed line), a detection limit of $c=1.3 \mathrm{fM}$ can be specified. Figure adapted from (ref. 21). restricts the excitation volume to a diameter of around $100 \mathrm{~nm}$, analogous to zero-mode waveguides. In STED, the restriction is achieved with a pair of laser pulses. The first focused excitation laser pulse is followed by a STED pulse for efficient de-excitation of the previously excited fluorophores, resulting in a residual excited volume of sub-wavelength diameter. ${ }^{31,32}$ In combination with raster scanning, super-resolution images can be obtained for the diffusion of individual lipid and protein molecules within the plasma membrane of living cells. ${ }^{33}$ The concept of STED has also been used for generating arrays of binding sites that can be decorated with single protein molecules, ${ }^{22}$ as discussed in the next chapter.

The other super-resolution microscopy methods rely on the sequential activation of photoswitchable fluorophores and subsequent single-molecule imaging. In photoactivated localization microscopy (PALM) ${ }^{34,35}$ fluorescent dyes are activated using a laser pulse. The illumination time and intensity is chosen to limit the density of activated fluorophores to a sufficiently small number which can be detected with optical, diffraction-limited imaging systems. ${ }^{36}$ Utilizing PALM for timeresolved super-resolution microscopy was made possible by an engineered fluorescent protein which is sufficiently photostable to enable localization with high precision yet amenable to efficient photo-deactivation to achieve a high contrast between the on and off state.

Stochastic optical reconstruction mircoscopy (STORM) ${ }^{37}$ is the second method of generating a sparse set of active fluorophores. As the probe, a pair of Cy3 and Cy5 fluorophores is used. Cy5, excited using a red laser, is imaged till it switches to its dark state. Exposing the Cy3-Cy5 pair to a green laser converts Cy5 back to its fluorescent state. The process can be repeated hundreds of times before irreversible photobleaching occurs. Recently, STORM has been utilized for measuring mRNA levels within intact cells in a parallel manner. ${ }^{38}$ Utilizing the resolution power of STORM in combination with 7 superresolution fluorophore pairs for spectral barcoding, 32 genes in individual $S$. cerevisiae cells could be quantified. The concept of STORM has been extended to $3 \mathrm{D}$-imaging ${ }^{39}$ to monitor the dynamics of transferrin and clathrin-coated pits in live cells. ${ }^{40} \mathrm{~A}$ simplified version of STORM called direct STORM (dSTORM) utilizes conventional cyanine dyes (Cy5, Alexa647). ${ }^{41}$ The reversible switching between dark and fluorescent state is achieved by illumination with $647 \mathrm{~nm}$ (turn dark) and $514 \mathrm{~nm}$ (turn fluorescent) laser light, respectively. Using dSTORM, the dynamics of protein complexes within cells has been imaged with $20 \mathrm{~nm}$ resolution and movements with $3 \mathrm{~nm} \mathrm{~s}^{-1}$ could be captured. ${ }^{42}$

The last technique for high-resolution fluorescence detection is NSOM. ${ }^{\mathbf{4 3 , 4 4}}$ Here, visible light from an optically coated fiber emanates from an aperture of a few tens of nm to illuminate a small volume. Raster scanning with the probe allows imaging of micrometer-sized samples with high sub-wavelength resolution and single fluorophore sensitivity ${ }^{45}$ as shown for DNA $^{46}$ and membrane-diffusing lipids. ${ }^{47}$

Information on other optical single-molecule detection assays in bioanalytical applications as well as advantages and limitations of corresponding ultrasensitive detection techniques are provided in several reviews. ${ }^{\mathbf{4 8 4}}$ 
The non-optical scanning probe approach of atomic force microscopy (AFM) is the most popular method for analyzing the shape, dimensions, and intramolecular and intermolecular forces of individual molecules. ${ }^{50}$ Among the many AFM variants and modes, three are most relevant for biopolymers. For molecular recognition, surface-bound biomolecules can be detected by cognate receptor molecules tethered to the AFM tip. ${ }^{51}$ This imaging can be combined with the regular topographic mode. ${ }^{52}$ Another related variant termed force spectroscopy, does not provide visual information in terms of lateral scans but studies the force-dependent interactions between individual surface-bound molecules and a receptor-coated cantilever $^{53,54}$ or within individual biological molecules ${ }^{55}$ to elucidate energetic, dynamic, and structural aspects of molecular processes such as DNA unzipping ${ }^{56}$ or protein unfolding. ${ }^{57,58}$ Finally, the slow-scanning read-out of serial AFM is being overcome by high-speed atomic force microscopy. This mode allows direct visualization of dynamic structural changes and dynamic processes of functioning biological molecules in physiological solutions and at high spatiotemporal resolution. ${ }^{59,60}$

\section{Single-molecule arrays}

This chapter describes the generation and different applications of single-molecule arrays. What constitutes these regular assemblies? In keeping with the format of conventional microarrays, single-molecule arrays can be understood as spatially defined and usually regular alignments of individually discernible molecules on planar surfaces. Indeed, single-molecule arrays represent the endpoint of a trajectory which has started with DNA and protein microarrays and has led to nanoarrays featuring a small number of molecules per spot. It is, however, also clear that the concept of planar assemblies has to be expanded into 3D to include nanotopographical surfaces and arrays of nanoparticles, beads and lipid vesicles which carry or contain individual biomolecules.

How, and how easily, can single-molecule arrays be generated? Their fabrication can be challenging due to the experimental difficulty in handling and positioning individual biomolecules. Several established nanopatterning methods ${ }^{61-64}$ can be adapted to achieve this aim. In general, arrays of biopolymers can be obtained following one of the two routes of nanopatterning, namely top-down or bottom-up. ${ }^{63,64}$

\section{Top-down}

In the top-down route, nanopatterns are made by physical or physico-chemical methods employing macroscopic tools. The large variety of top-down approaches can traditionally be further sub-categorized depending on whether the patterning is conducted in a serial fashion using e.g. an AFM cantilever or in a parallel fashion with a macroscale stamp. But this distinction has been blurred with the arrival of highly parallel AFM cantilever arrays. ${ }^{65}$

Given this Highlight's focus on the positioning of individual molecules, a different criterion is used. The distinction is made between the direct and indirect deposition. In the direct route, target biopolymers are transferred from a nanoscale carrier onto an otherwise unstructured surface. By comparison, in the indirect route molecules specifically adsorb from solution onto nanoscale sites of a pre-structured substrate.

Representative methods for the first, direct approach use a biomolecule-filled nanopipette which ejects individual or small numbers of biopolymer molecules. ${ }^{66}$ Other nanoscale carriers are "dip-pen" AFM cantilevers which are "inked" with biopolymers ${ }^{67}$ to transfer them onto the substrate upon writing. Deposition may also be achieved in a more parallel fashion with arrays of AFM cantilevers or via contact printing with nanostructured stamps ${ }^{68,69}$ which may optionally be assembled from microscale particles. ${ }^{70}$

For indirect patterning, biomolecules bind to chemically or electrostatically adhesive nanopatterns. Patterning with a chemical nanopatch was, for example, achieved with serial AFM-based nanografting where the cantilever scratches a hole into a surface-passivating layer to expose an adhesive nanopatch onto which individual biomolecules can bind..$^{10,71,72}$ Similarly, the AFM-based dip-pen nanolithography can generate nanopatterns of organic capture molecules for the immobilization of target biomolecules. ${ }^{73-75}$ The adhesive nanoislands can also be generated with complementary parallel methods including classical procedures and variants of e-beam and UV lithography, ${ }^{76-82}$ nanoimprint lithography, ${ }^{83}$ and the above mentioned nanocontact printing. ${ }^{84}$

Several of the methods have been used to generate singlemolecule arrays. A few reports are highlighted here. In the direct deposition route, individual nucleic acid molecules are positioned onto a substrate by taking advantage of the precision of

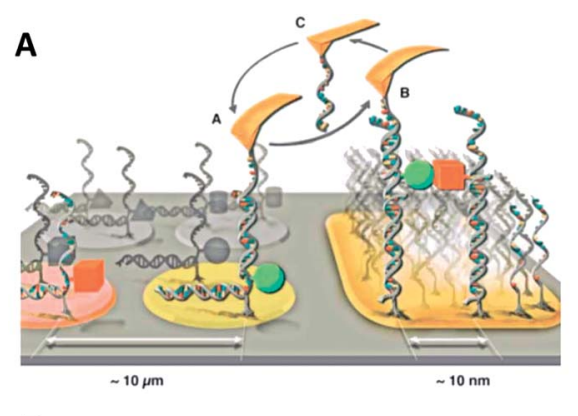

B

C
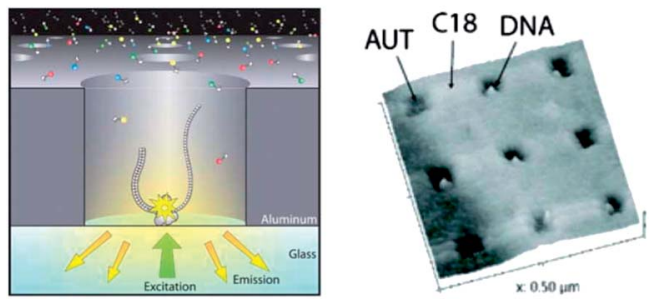

Fig. 2 Top-down approaches for the patterning of single molecules on surfaces. (A) Copy-paste of DNA strands with a capture-DNAmodified AFM cantilever. ${ }^{60}$ (B) Zero-mode waveguides carrying a single DNA strand within a nanocavity. ${ }^{28}$ (C) AFM image of a nanografted surface pattern carrying individual DNA duplexes within the scratched holes. ${ }^{10}$ 
AFM (Fig. 2A). Using a copy-and-paste approach based on reversible hybridization, DNA oligomers were picked up from a depot area on a chip by means of a complementary DNA strand which had been tethered to an AFM tip. ${ }^{67,85}$ The picked-up strands were then transferred to and deposited on a target area by formation of a more stable duplex with a substrate-immobilized capture strand. The approach helped create simple geometrical structures assembled from the single-molecule units. To confirm that individual molecules had been transferred, each cut-and-paste transfer event was characterized by single-molecule force spectroscopy and single-molecule fluorescence microscopy.

In comparison to the rather time-consuming nature of the direct deposition route, the complementary indirect route can bind in highly parallel fashion, molecules to millions of predefined sites on a nanopatterned substrate. Key to achieving the desired stoichiometry of one molecule per nanosite is to limit the dimensions of the latter to those of the former. Hence, arraying large biopolymers with a diameter of around $100 \mathrm{~nm}$ is easier than those of $5 \mathrm{~nm}$ because substrate patterns with feature sizes of $100 \mathrm{~nm}$ are more readily fabricated. In one example of the indirect deposition of large particles, individual single stranded DNA molecules resembling nanoballs of 300 $\mathrm{nm}$ diameter were immobilized onto lithographically generated nanodisks of equal diameter. ${ }^{7}$ The nanoballs were formed due to the engineered presence of self-complementary sequence elements which caused DNA to fold back onto itself. Electrostatic interaction caused the negatively charged nucleic acid nanoball to bind to the organically coated and positively charged surface nanopatches. The arraying of DNA was carried out to facilitate single-molecule sequencing-by-synthesis. Similar to related assays, the template-directed incorporation of fluorescent nucleotides into the nascent DNA was monitored. The new aspect was that each DNA strand contained concatenated copies of the same DNA sequence, thereby increasing the signal-to-noise ratio as multiple identical molecular fluorescence reactions took place per nanospot. Positioning DNA nanoballs in the array format had the added benefit of increasing their surface density resulting in a higher throughput in read-out compared to random, less dense biomolecule assemblies.

DNA strands were also immobilized onto size-matched nanopatterns in another sequencing approach based on zeromode waveguides. In these analysis platforms, a glass slide is coated with a $100 \mathrm{~nm}$-thick aluminum layer which contains an array of holes $70 \mathrm{~nm}$ across which is similar to the size of the analyzed DNA duplexes (Fig. 2B). For sequence-bysynthesis, a DNA polymerase is first immobilized at the bottom of the nanocavities to capture. In a second step, individual DNA strands at a $1: 1$ stoichiometry per well. ${ }^{28}$ The zero-mode waveguides limit the fluorescence excitation volume to a few zeptoliters to enable the use of $\mu \mathrm{M}$ concentrations of fluorescence-labeled deoxyribonucleotides. These high concentrations are required to drive enzymatic polymerization.

Smaller biopolymers have been arrayed by decreasing the size of the nanopatterns, as illustrated for a double stranded
DNA of 100 base pairs or around $30 \mathrm{~nm}$ length. In this case, the indirect deposition method of AFM nanografting was employed. ${ }^{10}$ A film of octadecanethiol was first physisorbed onto an atomically flat gold substrate to create a non-adsorptive layer. Patches of this film around $50 \mathrm{~nm}$ in size were subsequently scratched away with the AFM cantilever to expose the underlying adhesive gold surface. Incubating the holes with a solution of thiolated DNA duplexes led to the binding of individual molecules (Fig. 2C). To avoid immobilization of multiple strands, an excess of positively charged alkanethiol was added to coat the remaining areas of bare gold. The formed positive patch also electrostatically stabilized the binding of the DNA duplex to the surface. The DNA duplexes were visualized by AFM. In further studies, the individualized DNA strands were observed within the controlled nanoscale environment thereby helping to decouple the intrinsic properties from the heterogeneity caused by the local environment. ${ }^{\mathbf{9}, 10}$

Compared to relatively large DNA duplexes, the immobilization of individual smaller protein molecules requires the generation of nanospots which approach or match the size of protein targets. In one example, a few to individual antibody molecules of 10-15 $\mathrm{nm}$ size were immobilized on small polymeric nanopatches of 60-70 $\mathrm{nm}$. Arrays of the nanofeatures were fabricated by photo-polymerizing acrylic precursors with a two-photon STED technique ${ }^{22}$ which was originally developed for high-resolution fluorescence microscopy. The adsorbed antibodies remained bioactive as shown by probing their interaction with the cognate antigen which was located within bilayer membranes.

In another study, the immobilization sites were sub-ten $\mathrm{nm}$ gold nano-particles. The small particles were generated by scanning probe block copolymer lithography. ${ }^{86}$ In this specific form of dip-pen lithography, polymers chelated with metal ions are deposited on a chip and later annealed and reduced to form the metal particles. Proteins were immobilized on top of gold crystal scaffolds via an intermediary alkylthiol monolayer. The number of immobilized proteins was found to depend on the particles' size; when the nanospheres' size approached the dimensions of a protein molecule, each gold scaffold supported a single protein. This was demonstrated with both gold nanoparticle and quantum dot labeling coupled with transmission electron microscopy imaging experiments. The immobilized proteins remained bioactive, as shown by enzymatic assays and antigen-antibody binding experiments.

The concept of immobilizing biomolecules on spherical templates has also been exploited with larger microscale beads. Unlike the previous method of immobilization on top of the nanoscaffold, individual DNA strands were beneath the microspheres as they function as a molecular tether to the underlying nanopatterned substrate prepared by contact printing. ${ }^{87}$ The interfacial position was central in achieving a $1: 1$ stoichiometry because, following Poisson distribution, only one to a few DNA strands on the curved bead surface were physically proximal to the planar substrate. Hence, the density of biomolecules on the bead surface is an important parameter to achieve singlemolecule arrays. ${ }^{\mathbf{8}}$ The particular DNA-bead array was used to 
measure the variation in the effective length of the DNA tether. The experimental observable was the Brownian motion of the beads. This helped to uncover biophysical changes to the DNA structure which were induced by interaction with proteins. The advantage of the single-molecule array was an increased data output for the parallel force spectroscopy as opposed to conventional time-consuming serial assays.

Apart from the immobilization on surfaces of physically hard planar or curved substrates, arrays have also been obtained with soft spherical bilayer vesicles or water-in-oil droplets. Encapsulation in aqueous environments can help maintain the biomolecules' activity or structural integrity which may otherwise suffer by immobilization on inorganic substrates. ${ }^{89}$ The fragile fluid compartments require, however, careful patterning approaches. In one study, lipid bilayer vesicles have been assembled on microstructured substrates via multiple DNA duplexes formed by oligonucleotide anchors. ${ }^{90} \mathrm{With}$ water-in-oil droplets, the assembly was shown to take place on hydrophilichydrophobic micropatterned surfaces ${ }^{91}$ which were optionally linked to fiber optic arrays for direct optical readout. ${ }^{92,93}$ When applied to encapsulated enzymes, the atto- to femtoliter nanoreactors enabled single-molecule kinetics studies in a highly parallel format. ${ }^{93}$ The signal of individual enzymes was amplified by fluorogenic substrates. ${ }^{91-93}$

It is noted that in the above mentioned micro-sized droplets and vesicles, single molecules are no longer present at a $1: 1$ stoichiometry but Poisson-distributed because the nanocontainers are larger than the proteins which removes the sizedependent restriction of other physically hard nanopatterns such as zero-mode waveguides. In another variant droplet array, water-in-oil vesicles are mixed with phospholipids to form a lipid-monolayer lining the water-oil interface. When droplets are in physical contact, a bilayer is formed. ${ }^{94,95}$ Individual protein channels can insert at the interface bilayer leading to electrically detectable channel networks. ${ }^{96}$

Lipid bilayers in the planar rather than vesicular form have also been exploited for single-molecule studies. By their nature, planar bilayer arrays are ideal to study membrane proteins including ion channels and nanopores with microscopic techniques. Planar arrays have been created by layering membranes on microstructured solid substrates and, ${ }^{97-101}$ more recently, by spanning them across water-filled cavities. ${ }^{\mathbf{1 0 2}-104}$ The latter format is scientifically attractive as the absence of any underlying solid support enables the integral membrane protein to freely diffuse in the bilayer thereby mimicking their natural biophysical behavior. As an additional benefit, powerful singlechannel current analysis can examine ion channels and nanopores provided the bilayer is formed over cavities containing individual microelectrodes. ${ }^{102-104}$ These chip-based nanopore microarrays are important as they enable the parallel highresolution electrical analysis of channels as well as analytes which pass through individual protein nanopores. In future, the bilayer arrays will likely play an important role in the sequencing of single DNA strands by nanopore recording. ${ }^{105,106}$ In this respect, arrays of top-down fabricated solid-state nanopores are also mentioned ${ }^{107-109}$ even though they are not yet able to distinguish individual bases.

\section{Bottom-up}

The top-down route towards single-molecule arrays is complemented by bottom-up self-assembled lattices. Top-down methods are excellent for periodicities from the microscale down to around $50 \mathrm{~nm}$, but the range from $50 \mathrm{~nm}$ to $1 \mathrm{~nm}$ is accessible via bottom-up routes. In general, self-assembly is a remarkable process and can lead to the formation of planar arrays on interfaces as shown for nucleotides, ${ }^{110}$ small organic aromatic molecules, ${ }^{111}$ organic polymers, ${ }^{13}$ and inorganic particles. ${ }^{12}$ Natural and engineered proteins $s^{113-115}$ and DNA nanostructures ${ }^{116-119}$ also form lattices but do not require solid supports because the biopolymers' sophisticated structure enables a lock-and-key-like interaction of the subunits during self-assembly.

Among the most prominent proteins capable of self-assembling into planar lattices are bacterial s-layers. These protein arrays constitute the outermost cell-wall coat of many bacteria and all archaea and form, in most cases, by self-assembly of a single protein species. ${ }^{120}$ Relevant for patterning purposes, protein subunits are arranged in different lattice symmetries (oblique, square or hexagonal) and are separated by inter-subunit distances which vary between 2 and $20 \mathrm{~nm}$ depending on the Slayer type. ${ }^{113,121,122}$ The proteins also self-assemble in vitro into microscale products. ${ }^{123,124}$ The structures of different lattices have been visualized with AFM and electron microscopy at nanoscale resolution, and, more recently, with X-ray crystallography to atomic resolution (Fig. 3A). ${ }^{125}$ The availability of the detailed molecular picture will facilitate rational engineering of S-layers but is also an achievement in itself. In particular, the recent X-ray study has overcome the inherent difficulty ${ }^{126,127}$ of obtaining 3D lattices from protein that naturally assembles into $2 \mathrm{D}$ lattices.
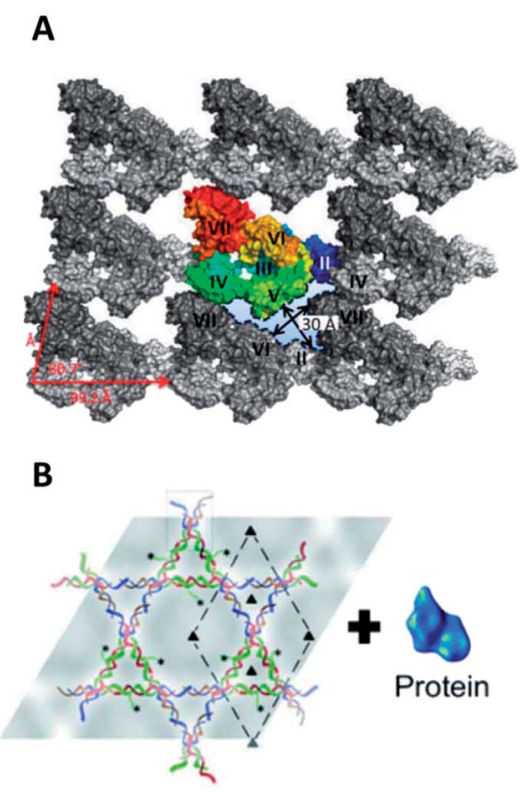

Fig. 3 Bottom-up biopolymer assemblies. (A) Molecular model of the S-layer lattice from Geobacillus stearothermophilus obtained by fitting the $\mathrm{X}$-ray structure of an assembly-blocked protein into cryo-EM of the native lattice. ${ }^{125}$ (B) DNA nanoaffinity templates create dense, nonoverlapping arrays of protein molecules. ${ }^{128}$ 
How can individual molecules be immobilized on S-layers and used for the purpose of single-molecule arrays? The attachment of molecules to the lattices can, similar to the topdown approach, proceed in direct and indirect fashion. In the context of bottom-up, it implies linking the cargo to the S-layer subunits either before or after lattice assembly, respectively.

Given the defined nanoscale and repetitive structure, S-layer lattices can immobilize proteins or vaccine epitopes in high nanoscale density ${ }^{\mathbf{1 2 0}}$ thereby mimicking one of their natural functions as immobilization matrices for exoenzymes. ${ }^{129,130}$ In another application, the single-molecule periodicity of the engineered S-layers was more fully exploited to provide a reference structure to evaluate the resolution of an AFM technique. ${ }^{\mathbf{1 3 1 , 1 3 2}}$ Specifically, a lattice displaying peptide tags helped demonstrate an imaging mode where the cognate receptor is attached to the AFM tip. By using read-out via simultaneous topography and recognition imaging, the nanoarray confirmed the validity of the high-resolution approach by yielding maps of the affinity sites with a positional accuracy of $1.5 \mathrm{~nm}$. In a related study, protein affinity arrays were prepared by cloning streptavidin domains. ${ }^{133}$ While useful, one of the drawbacks of S-layers is their somewhat limited and locked-in lattice periodicity. Consequently, there is interest to obtain biomolecular arrays with tunable spacing. Different types of protein arrays other than the S-layer are available ${ }^{\mathbf{1 1 4}}$ but these are similarly restrained in lattice symmetries.

An attractive alternative to protein-based lattices are DNA nanoarrays. ${ }^{134}$ These nanostructures are more flexible with regard to spacing and geometry. Structurally defined DNA nanoarrays can be generated by sequence-specific self-assembly of component DNA strands. Assembly can be pursued following two main routes that differ with regard to the type of building blocks. In the first case, the smaller units are DNA tiles of about $10 \mathrm{~nm}$ size which are assembled from synthetic DNA oligonucleotides. One widely used type of DNA tile contains two parallel aligned duplexes connected by a double-crossover (DX) motif ${ }^{116}$ but other tiles with alternating geometries exist. ${ }^{116,117}$ To facilitate assembly into larger structures, DNA tiles can be equipped with DNA overhangs of complementary sequence. ${ }^{\mathbf{1 3 5}}$ The resulting pattern can be around hundreds of micrometers large $\mathrm{e}^{\mathbf{1 1 8 , 1 3 5}}$ but are usually highly repetitive. ${ }^{\mathbf{1 3 6 , 1 3 7}}$ Indeed, the tiles can be assembled into highly ordered 3D lattices suitable for analysis by X-ray crystallography. ${ }^{\mathbf{1 3 8}}$

A second type of DNA assembly can overcome this repetitiveness. Unlike tiles, the so-called origami nanostructures are formed by hybridizing at least one long DNA scaffold strand and several smaller oligonucleotide staple strands. ${ }^{139-141}$ Benefits of the origami design include a larger unit size of up to $100 \mathrm{~nm}$ and the engineering of unique non-repetitive sites which stem from the use of unique DNA sequences. Due to their large size, the origami structures already constitute arrays. However, they can also be used as building blocks to assemble larger lattices, similar to DNA tiles. This can be achieved by connecting origami either via sticky DNA ends, ${ }^{142}$ complementary concave and convex edges similar to pieces of a jigsaw puzzle, ${ }^{\mathbf{1 4 3}}$ or by using a preformed DNA-based scaffold frame onto which smaller origami units can latch. ${ }^{144}$ The DNA scaffold can also be designed to achieve curved shapes. ${ }^{145}$
In one variant route, DNA origami-type structures can be assembled without the use of a long DNA scaffold thereby increasing flexibility in design. Rather, the architectures are formed solely from single-stranded DNA molecules. These small bricks have no ordered structure before they are incorporated into the superstructure. ${ }^{\mathbf{1 4 6}}$ Nevertheless, hundreds of bricks were incorporated into a 2D lattice comparable in size to that of classical 2D DNA origami. ${ }^{147}$ The brick-based strategy is also suitable to form 3D architectures ${ }^{\mathbf{1 4 8}}$ including membranespanning nanopores which require chemically modified DNA strands. ${ }^{149,150}$

How can individual molecules be attached to DNA arrays? Cargo molecules can be placed at predefined sites via reactive chemical functional or bioaffinity groups. These functional moieties can be incorporated into the lattice by means of chemically modified DNA oligonucleotides that carry thiol, amino, and azide groups, or bioaffinity tags such as biotin or DNA strands. Cargo can be incorporated into the array either prior to or after assembly, corresponding to the direct or indirect route, respectively. The former strategy is ideal for small molecules such as fluorescent dyes, while the latter is preferred for large cargoes which would otherwise interfere with lattice assembly. Indeed, DNA lattices have been used as templates to form arrays of gold nanoparticles, ${ }^{151,152}$ quantum dots, ${ }^{153}$ or other nanoparticles, ${ }^{154,155}$ as well as proteins ${ }^{156-159}$ and DNA. ${ }^{118,135}$

What can DNA arrays be used for? Placing individual molecules in regular $2 \mathrm{D}$ crystalline lattices has been exploited in structural biology to aid the investigation of a protein's molecular architecture. ${ }^{128}$ Usually, cryomicroscopy examines noncrystalline protein samples by image reconstruction from noisy snap-shots of individual proteins. The random distribution of the sample is, however, associated with problems in image processing. Positioning thousands of proteins in a defined orientation via a DNA tile template (Fig. 3B) overcomes these hurdles by greatly facilitating data collection, as illustrated with a G-protein-coupled membrane receptor, a soluble G-protein, and their binary complex. ${ }^{\mathbf{2 8}}$

In other applications, DNA arrays were used as molecular pegboards for placing fewer molecules at pre-defined yet tunable sites and distances. Particularly versatile in this respect are planar DNA origami squares or rectangles of around $100 \mathrm{~nm}$ in length, although other shapes are possible. ${ }^{\mathbf{1 4 0 , 1 6 0}}$ These platforms have opened up many exciting applications in biophysics, chemistry, fluorescence microscopy, and nanobiotechnology. In biophysics, a flat DNA rectangle was equipped with arrays of two molecular recognition motifs separated by variable distance. This helped probe the spacing-dependent binding of bivalent analytes and shed light on the biophysics of this process. ${ }^{161}$ In chemistry, diffusion of a reactive oxygen species was studied as a function of the nanoscale distance between a light-activated photosensitizer and corresponding photocleavable moieties suitable for AFM read-out. ${ }^{\mathbf{1 6 2}}$ For super-resolution fluorescence microscopy, DNA arrays were equipped with single fluorophores at defined nanoscale distances to serve as reference standards. ${ }^{29}$ Fluorophore pairs were also used for FRET studies. ${ }^{\mathbf{1 6 3}}$ An exciting development is the use of DNA arrays to enhance fluorescence by metallic nanoparticles which set up a 
plasmonic hotspot of zeptoliter volume. These nanoantennas were prepared by attaching two gold nanoparticles onto a pillarlike DNA origami structure, which also incorporated a docking site for a single fluorescent dye in the gap between the two particles. ${ }^{164}$ In nanobiotechnology, the placement of individual protein $^{\mathbf{1 4 0 , 1 6 5}}$ and DNA molecules onto defined sites of DNA origami has led to artistically ambitious or dynamic nanopatterns. In graphically inspired experiments, individual proteins were used as pixels to draw a nanoscale version of a smiling human face. ${ }^{\mathbf{1 4 0 , 1 6 5}}$ By comparison, in a dynamic patterning approach ${ }^{\mathbf{1 6 6}}$ single stranded DNA extensions functioned as tracks to guide the movement of individual molecular spiders. The legs of the spider were single stranded DNA which hybridized to the DNA guides. The resulting duplexes could be enzymatically cleaved to release the full-length spider legs to achieve directional movement. ${ }^{167}$ DNA arrays displaying individual DNA molecules have been exploited for other forms of robotic movement. ${ }^{168,169}$

\section{Conclusions and prospects}

This Highlight has described the exciting interface between single-molecule sensing and biomolecular arrays. This combination of two research areas has led to many new scientific insights and methodological developments. But how widespread is the ultrasensitive analysis of conventional microarrays in research settings? Which role do single-molecule arrays play in the competitive commercial markets of sequencing and diagnostics as well as in academic laboratories?

As detailed above, the single-molecule readout of conventional microarrays was pioneered several years ago and yielded tangible analytical benefits in terms of detection limit and dynamic range. But scanning of slides down to the singlemolecule level has not been taken up by many other research groups. Possible reasons include the technological lock-in onto conventional array formats which can use glass substrates of several $\mathrm{mm}$ thickness. By contrast, the ultrasensitive scanning via wide-field fluorescence microscopy requires glass thicknesses of around $150 \mu \mathrm{m}$. Their more wide-spread use requires the development of easy-to-use single-molecule microarray analysis platforms. For hypothesis-free screening on unknown or mutated targets, microarrays are being gradually replaced by modern sequencing techniques.

By comparison, single-molecule arrays have made inroads into sequencing applications. The high through-put for singlemolecule analysis has been exploited in DNA-nanoball arrays, zero-mode waveguides, and highly parallel nanopore recordings. Other advantages for sequencing in array format include lowered reagent consumption, as well as reduced and amplification-free processing of samples. The more wide-spread use of these single-molecule techniques is also facilitated by the fact that sequencing technology is usually located in a few sequencing centers and operated by dedicated staff. While the methods are either close to or already commercially available, they face strong competition from other non-single-molecule sequencing techniques. ${ }^{106}$
Commercial interest into single-molecule arrays also exists in the field of diagnostics. Here, one trend is the use of beadbased arrays in combination with an integrated read-out mode to span the extremes between single molecules and saturating analyte concentrations. For example, a dynamic sensing range of over 6 orders of magnitude was achieved for the diagnostically important prostate-specific antigen. ${ }^{\mathbf{1 7 0 , 1 7 1}}$ The impressive results were achieved by capturing the analytes on the beads with a conventional immune-sandwich assay, singulating individual beads within an array of 50 femtoliter wells, and detecting bead-associated enzymatic activity by fluorescence scanning. At lower analyte concentrations, individual molecules were counted while at higher concentrations the fluorescence intensity per bead was averaged. ${ }^{\mathbf{1 7 0 , 1 7 1}}$ The spread of singlemolecule diagnostics into point-of-care settings will likely be facilitated by several other developments including singlemolecule detectors with a small footprint, ${ }^{172}$ fluorescenceenhancing nanostructured metal surfaces to ease detection with less costly equipment, ${ }^{173}$ and software to simplify the processing of large single-molecule data sets for improved format standardization, easier dissemination, and transparent analysis. ${ }^{\mathbf{1 7 4}}$

Within academic laboratories, single-molecule arrays have been used by many groups for biophysical and, to a lesser extent, for cell biological research. While it is difficult to predict specific topics in future research, existing studies suggest that arrays of single molecules with microscale periodicities can boost cell biological investigations. Once successfully prepared, the proposed arrays could also fill gaps in the range of currently available formats. Possible technological routes towards the micro single-molecule arrays will likely rely on the synergistic combination of top-down patterns of $50 \mathrm{~nm}$ feature size with bottom-up atomically precise DNA nanostructures of $50 \mathrm{~nm}$ size. For example, the top-down-generated nanopatterned surfaces could be decorated with structurally fine-tuned DNA nanoarchitectures displaying individual molecules. Existing reports have demonstrated the principle of this route ${ }^{175,176}$ but further research is required to attain the proposed single-molecule arrays.

In conclusion, the ultrasensitive scanning of arrays and the development of single-molecule arrays has had an impact on scanning, sequencing and diagnostics and opened up the opportunity to address many previously unexplored biophysical and biological phenomena.

\section{Acknowledgements}

This work has been supported by the Leverhulme Trust (RPG170), the EPSRC (Institutional Sponsorship Award), UCL Chemistry, the National Physical Laboratory, the Austrian Science Foundation (project P25730-B21), the government of Upper Austria, the European Funds for regional development (EFRE), and the European Community's Seventh Framework Programme (FP7/2007-2013) under grant agreement no. 278403.

\section{Notes and references}

1 M. Schena, D. Shalon, R. W. Davis and P. O. Brown, Science, 1995, 270, 467-470. 
2 S. P. Fodor, R. P. Rava, X. C. Huang, A. C. Pease, C. P. Holmes and C. L. Adams, Nature, 1993, 364, 555-556.

3 G. MacBeath and S. L. Schreiber, Science, 2000, 289, 17601763.

4 J. P. Pellois, X. Zhou, O. Srivannavit, T. Zhou, E. Gulari and X. Gao, Nat. Biotechnol., 2002, 20, 922-926.

5 S. Fukui, T. Feizi, C. Galustian, A. M. Lawson and W. Chai, Nat. Biotechnol., 2002, 20, 1011-1017.

6 J. Zlatanova and K. van Holde, Mol. Cell, 2006, 24, 317329.

7 R. Drmanac, A. B. Sparks, M. J. Callow, A. L. Halpern, N. L. Burns, B. G. Kermani, P. Carnevali, I. Nazarenko, G. B. Nilsen, G. Yeung, F. Dahl, A. Fernandez, B. Staker, K. P. Pant, J. Baccash, A. P. Borcherding, A. Brownley, R. Cedeno, L. Chen, D. Chernikoff, A. Cheung, R. Chirita, B. Curson, J. C. Ebert, C. R. Hacker, R. Hartlage, B. Hauser, S. Huang, Y. Jiang, V. Karpinchyk, M. Koenig, C. Kong, T. Landers, C. Le, J. Liu, C. E. McBride, M. Morenzoni, R. E. Morey, K. Mutch, H. Perazich, K. Perry, B. A. Peters, J. Peterson, C. L. Pethiyagoda, K. Pothuraju, C. Richter, A. M. Rosenbaum, S. Roy, J. Shafto, U. Sharanhovich, K. W. Shannon, C. G. Sheppy, M. Sun, J. V. Thakuria, A. Tran, D. Vu, A. W. Zaranek, X. Wu, S. Drmanac, A. R. Oliphant, W. C. Banyai, B. Martin, D. G. Ballinger, G. M. Church and C. A. Reid, Science, 2010, 327, 78-81.

8 A. Ishijima and T. Yanagida, Trends Biochem. Sci., 2001, 26, 438-444.

9 E. A. Josephs and T. Ye, Nano Lett., 2012, 12, 5255-5261.

10 E. A. Josephs and T. Ye, J. Am. Chem. Soc., 2010, 132, 1023610238.

11 A. Graslund, R. Rigler and J. Widengren, Single Molecule Spectroscopy in Chemistry, Physics, and Biology, Springer, Berlin, 2010.

12 A. W. Peterson, L. K. Wolf and R. M. Georgiadis, J. Am. Chem. Soc., 2002, 124, 14601-14607.

13 J. D. Ding, J. H. Huang, S. V. Grater, F. Corbellinl, S. Rinck, E. Bock, R. Kemkemer, H. Kessler and J. P. Spatz, Nano Lett., 2009, 9, 1111-1116.

14 H. Agheli, J. Malmstrom, E. M. Larrson, M. Textor and D. S. Sutherland, Nano Lett., 2006, 6, 1165-1171.

15 K. L. Christman, V. Vazquez-Dorbatt, E. Schopf, C. M. Kolodziej, R. C. Li, R. M. Broyer, Y. Chen and H. D. Maynard, J. Am. Chem. Soc., 2008, 130, 16585-16591.

16 V. Vogel and M. Sheetz, Nat. Rev. Mol. Cell Biol., 2006, 7, 265-275.

17 M. P. Lutolf, P. M. Gilbert and H. M. Blau, Nature, 2009, 462, 433-441.

18 D. Aydin, V. C. Hirschfeld-Warneken, I. Louban and J. P. Spatz, in Intelligent Surfaces in Biotechnology: Scientific and Engineering Concepts, Enabling Technologies, and Translation to Bio-Oriented Applications, ed. H. M. Grandin and M. Textor, John Wiley \& Sons, Inc., Hoboken, NJ, USA, 2012, pp. 291-319.

19 R. Schlapak, P. Pammer, D. Armitage, R. Zhu, P. Hinterdorfer, M. Vaupel, T. Fruhwirth and S. Howorka, Langmuir, 2006, 22, 277-285.
20 J. Hesse, M. Sonnleitner, A. Sonnleitner, G. Freudenthaler, J. Jacak, O. Höglinger, H. Schindler and G. J. Schutz, Anal. Chem., 2004, 76, 5960-5964.

21 J. Hesse, J. Jacak, M. Kasper, G. Regl, T. Eichberger, M. Winklmayr, F. Aberger, M. Sonnleitner, R. Schlapak, S. Howorka, L. Muresan, A. M. Frischauf and G. J. Schutz, Genome Res., 2006, 16, 1041-1045.

22 M. Wiesbauer, R. Wollhofen, B. Vasic, K. Schilcher, J. Jacak and T. A. Klar, Nano Lett., 2013, 13, 5672-5678.

23 E. B. Shera, N. K. Seitzinger, L. M. Davis, R. A. Keller and S. A. Soper, Chem. Phys. Lett., 1990, 174, 553-557.

24 J. Jacak, H. Schnidar, L. Muresan, G. Regl, A. M. Frischauf, F. Aberger, G. J. Schütz and J. Hesse, J. Biotechnol., 2013, 164, 525-530.

25 R. Lebofsky, R. Heilig, M. Sonnleitner, J. Weissenbach and A. Bensimon, Mol. Biol. Cell, 2006, 17, 5337-5345.

26 R. Schlapak, H. Kinns, C. Wechselberger, J. Hesse and S. Howorka, ChemPhysChem, 2007, 8, 1618-1621.

27 M. J. Levene, J. Korlach, S. W. Turner, M. Foquet, H. G. Craighead and W. W. Webb, Science, 2003, 299, 682-686.

28 J. Eid, A. Fehr, J. Gray, K. Luong, J. Lyle, G. Otto, P. Peluso, D. Rank, P. Baybayan, B. Bettman, A. Bibillo, K. Bjornson, B. Chaudhuri, F. Christians, R. Cicero, S. Clark, R. Dalal, A. Dewinter, J. Dixon, M. Foquet, A. Gaertner, P. Hardenbol, C. Heiner, K. Hester, D. Holden, G. Kearns, X. Kong, R. Kuse, Y. Lacroix, S. Lin, P. Lundquist, C. Ma, P. Marks, M. Maxham, D. Murphy, I. Park, T. Pham, M. Phillips, J. Roy, R. Sebra, G. Shen, J. Sorenson, A. Tomaney, K. Travers, M. Trulson, J. Vieceli, J. Wegener, D. Wu, A. Yang, D. Zaccarin, P. Zhao, F. Zhong, J. Korlach and S. Turner, Science, 2009, 323, 133-138.

29 J. Vogelsang, C. Steinhauer, C. Forthmann, I. H. Stein, B. Person-Skegro, T. Cordes and P. Tinnefeld, ChemPhysChem, 2010, 11, 2475-2490.

30 S. W. Hell and J. Wichmann, Opt. Lett., 1994, 19, 780782.

31 M. Dyba and S. W. Hell, Phys. Rev. Lett., 2002, 88, 163901. 32 T. A. Klar, S. Jakobs, M. Dyba, A. Egner and S. W. Hell, Proc. Natl. Acad. Sci. U. S. A., 2000, 97, 8206-8210.

33 C. Eggeling, C. Ringemann, R. Medda, G. Schwarzmann, K. Sandhoff, S. Polyakova, V. N. Belov, B. Hein, C. von Middendorff, A. Schönle and S. W. Hell, Nature, 2009, 457, 1159-1162.

34 S. T. Hess, T. P. K. Girirajan and M. D. Mason, Biophys. J., 2006, 91, 4258-4272.

35 E. Betzig, G. H. Patterson, R. Sougrat, O. W. Lindwasser, S. Olenych, J. S. Bonifacino, M. W. Davidson, J. Lippincott-Schwartz and F. H. Hess, Science, 2006, 313, 1642-1645.

36 H. Shroff, C. G. Galbraith, J. A. Galbraith and E. Betzig, Nat. Methods, 2008, 5, 417-423.

37 M. J. Rust, M. Bates and X. Zhuang, Nat. Methods, 2006, 3, 793-795.

38 E. Lubeck and L. Cai, Nat. Methods, 2012, 9, 743-748.

39 B. Huang, W. Wang, M. Bates and X. Zhuang, Science, 2008, 319, 810-813. 
40 S. A. Jones, S.-H. Shim, J. He and X. Zhuang, Nat. Methods, 2011, 8, 499-508.

41 M. Heilemann, S. van de Linde, M. Schüttpelz, R. Kasper, B. Seefeldt, A. Mukherjee, P. Tinnefeld and M. Sauer, Angew. Chem., Int. Ed., 2008, 47, 6172-6176.

42 R. Wombacher, M. Heidbreder, S. van de Linde, M. P. Sheetz, M. Heilemann, V. W. Cornish and M. Sauer, Nat. Methods, 2010, 7, 717-719.

43 E. Betzig and J. K. Trautman, Science, 1992, 257, 189-195.

44 E. Betzig, A. Lewis, A. Harootunian, M. Isaacson and E. Kratschmer, Biophys. J., 1986, 49, 269-279.

45 E. Betzig and R. J. Chichester, Science, 1993, 262, 1422-1425.

46 J. M. Kim, T. Ohtani, J. Y. Park, S. M. Chang and H. Muramatsu, Ultramicroscopy, 2002, 91, 139-149.

47 C. Manzo, T. S. van Zanten and M. F. Garcia-Parajo, Biophys. J., 2011, 100, L8-L10.

48 D. R. Walt, Anal. Chem., 2013, 85, 1258-1263.

49 P. Holzmeister, G. P. Acuna, D. Grohmann and P. Tinnefeld, Chem. Soc. Rev., 2014, DOI: 10.1039/ C3CS60207A.

50 G. Binnig, C. F. Quate and C. Gerber, Phys. Rev. Lett., 1986, 56, 930-933.

51 V. Dupres, F. D. Menozzi, C. Locht, B. H. Clare, N. L. Abbott, S. Cuenot, C. Bompard, D. Raze and Y. F. Dufrene, Nat. Methods, 2005, 2, 515-520.

52 C. Stroh, H. Wang, R. Bash, B. Ashcroft, J. Nelson, H. Gruber, D. Lohr, S. M. Lindsay and P. Hinterdorfer, Proc. Natl. Acad. Sci. U. S. A., 2004, 101, 12503-12507.

53 V. T. Moy, E. L. Florin and H. E. Gaub, Science, 1994, 266, 257-259.

54 P. Hinterdorfer, W. Baumgartner, H. J. Gruber, K. Schilcher and H. Schindler, Proc. Natl. Acad. Sci. U. S. A., 1996, 93, 3477-3481.

55 A. F. Oberhauser, P. E. Marszalek, H. P. Erickson and J. M. Fernandez, Nature, 1998, 393, 181-185.

56 M. Rief, H. Clausen-Schaumann and H. E. Gaub, Nat. Struct. Biol., 1999, 6, 346-349.

57 R. Merkel, P. Nassoy, A. Leung, K. Ritchie and E. Evans, Nature, 1999, 397, 50-53.

58 F. Oesterhelt, D. Oesterhelt, M. Pfeiffer, A. Engel, H. E. Gaub and D. J. Muller, Science, 2000, 288, 143-146.

59 T. Ando, Nanotechnology, 2012, 23, 062001.

60 I. Casuso, F. Rico and S. Scheuring, Curr. Opin. Chem. Biol., 2011, 15, 704-709.

61 K. L. Christman, V. D. Enriquez-Rios and H. D. Maynard, Soft Matter, 2006, 2, 928-939.

62 C. M. Niemeyer, Science, 2002, 297, 62-63.

63 C. M. Niemeyer and C. A. Mirkin, Nanobiotechnology: Concepts, applications and perspectives, John Wiley \& Sons, 2004.

64 C. A. Mirkin and C. M. Niemeyer, Nanobiotechnology II: More concepts and applications, John Wiley \& Sons, 2007.

65 K. Salaita, Y. Wang, J. Fragala, R. A. Vega, C. Liu and C. A. Mirkin, Angew. Chem., Int. Ed., 2006, 45, 7220-7223.

66 A. Bruckbauer, L. Ying, A. M. Rothery, A. I. Shevchuk, C. Abell, Y. E. Korchev and D. Klenerman, J. Am. Chem. Soc., 2002, 124, 8810-8811.
67 S. K. Kufer, E. M. Puchner, H. Gumpp, T. Liedl and H. E. Gaub, Science, 2008, 319, 594-596.

68 W. T. S. Huck, H. W. Li, B. V. O. Muir and G. Fichet, Langmuir, 2003, 19, 1963-1965.

69 H. Schmid and B. Michel, Macromolecules, 2000, 33, 30423049.

70 P. Pammer, R. Schlapak, M. Sonnleitner, A. Ebner, R. Zhu, P. Hinterdorfer, O. Höglinger, H. G. Schindler and S. Howorka, ChemPhysChem, 2005, 6, 900-903.

71 A. Tinazli, J. Piehler, M. Beuttler, R. Guckenberger and R. Tampe, Nat. Nanotechnol., 2007, 2, 220-225.

72 H. Artelsmair, F. Kienberger, A. Tinazli, R. Schlapak, R. Zhu, J. Preiner, J. Wruss, M. Kastner, N. Saucedo-Zeni, M. Hoelzl, C. Rankl, W. Baumgartner, S. Howorka, D. Blaas, H. Gruber, R. Tampe and P. Hinterdorfer, Small, 2008, 4, 847-854.

73 C. A. Mirkin, D. S. Ginger and H. Zhang, Angew. Chem., Int. Ed., 2004, 43, 30-45.

74 R. Valiokas, T. Rakickas, M. Gavutis, A. Reichel, J. Piehler and B. Liedberg, Nano Lett., 2008, 8, 3369-3375.

75 S. Lenhert, S. Sekula, J. Fuchs, S. Weg-Remers, P. Nagel, S. Schuppler, J. Fragala, N. Theilacker, M. Franueb, C. Wingren, P. Ellmark, C. A. K. Borrebaeck, C. A. Mirkin and H. Fuchs, Small, 2008, 4, 1785-1793.

76 J. Rundqvist, J. H. Hoh and D. B. Haviland, Langmuir, 2006, 22, 5100-5107.

77 R. Michel, I. Reviakine, D. Sutherland, C. Fokas, G. Csucs, G. Danuser, N. D. Spencer and M. Textor, Langmuir, 2002, 18, 8580-8586.

78 N. Reynolds, J. D. Tucker, P. A. Davison, J. A. Timney, C. N. Hunter and G. J. Leggett, J. Am. Chem. Soc., 2009, 131, 896-897.

79 S. Lata, A. Reichel, R. Brock, R. Tampe and J. Piehler, J. Am. Chem. Soc., 2005, 127, 10205-10215.

80 R. Schlapak, J. Danzberger, T. Haselgrubler, P. Hinterdorfer, F. Schaffler and S. Howorka, Nano Lett., 2012, 12, 1983-1989.

81 M. Bhagawati, S. Lata, R. Tampé and J. Piehler, J. Am. Chem. Soc., 2010, 132, 5932-5933.

82 C. M. Kolodziej and H. D. Maynard, Chem. Mater., 2012, 24, 774-780.

83 V. N. Truskett and M. P. C. Watts, Trends Biotechnol., 2006, 24, 312-317.

84 W. Shim, A. B. Braunschweig, X. Liao, J. Chai, J. K. Lim, G. Zheng and C. A. Mirkin, Nature, 2011, 469, 516-520.

85 S. K. Kufer, M. Strackharn, S. W. Stahl, H. Gumpp, E. M. Puchner and H. E. Gaub, Nat. Nanotechnol., 2009, 4, 45-49.

86 J. Chai, L. S. Wong, L. Giam and C. A. Mirkin, Proc. Natl. Acad. Sci. U. S. A., 2011, 108, 19521-19525.

87 T. Plenat, C. Tardin, P. Rousseau and L. Salome, Nucleic Acids Res., 2012, 40, e89.

88 M. J. Barrett, P. M. Oliver, P. Cheng, D. Cetin and D. Vezenov, Anal. Chem., 2012, 84, 4907-4914.

89 R. Schlapak, J. Danzberger, D. Armitage, D. Morgan, A. Ebner, P. Hinterdorfer, P. Pollheimer, H. J. Gruber, F. Schaffler and S. Howorka, Small, 2012, 8, 89-97. 
90 D. Stamou, C. Duschl, E. Delamarche and H. Vogel, Angew. Chem., Int. Ed., 2003, 42, 5580-5583.

91 S. Sakakihara, S. Araki, R. Iino and H. Noji, Lab Chip, 2010, 10, 3355-3362.

92 H. Zhang, S. Nie, C. M. Etson, R. M. Wang and D. R. Walt, Lab Chip, 2012, 12, 2229-2239.

93 Z. Li, R. B. Hayman and D. R. Walt, J. Am. Chem. Soc., 2008, 130, 12622-12623.

$94 \mathrm{~W}$. L. Hwang, M. Chen, B. Cronin, M. A. Holden and H. Bayley, J. Am. Chem. Soc., 2008, 130, 5878-5879.

95 M. A. Holden, D. Needham and H. Bayley, J. Am. Chem. Soc., 2007, 129, 8650-8655.

96 G. Maglia, A. J. Heron, W. L. Hwang, M. A. Holden, E. Mikhailova, Q. H. Li, S. Cheley and H. Bayley, Nat. Nanotechnol., 2009, 4, 437-440.

97 J. T. Groves, Curr. Opin. Drug Discovery Dev., 2002, 5, 606612.

98 T. Lohmuller, L. Iversen, M. Schmidt, C. Rhodes, H. L. Tu, W. C. Lin and J. T. Groves, Nano Lett., 2012, 12, 1717-1721. 99 S. G. Boxer, Curr. Opin. Chem. Biol., 2000, 4, 704-709.

100 J. S. Hovis and S. G. Boxer, Langmuir, 2001, 17, 3400-3405. 101 F. Roder, O. Birkholz, O. Beutel, D. Paterok and J. Piehler, J. Am. Chem. Soc., 2013, 135, 1189-1192.

102 T. Osaki, H. Suzuki, B. Le Pioufle and S. Takeuchi, Anal. Chem., 2009, 81, 9866-9870.

103 A. Kleefen, D. Pedone, C. Grunwald, R. Wei, M. Firnkes, G. Abstreiter, U. Rant and R. Tampe, Nano Lett., 2010, 10, 5080-5087.

104 G. Baaken, N. Ankri, A. K. Schuler, J. Ruhe and J. C. Behrends, ACS Nano, 2011, 5, 8080-8088.

105 D. Branton, D. W. Deamer, A. Marziali, H. Bayley, S. A. Benner, T. Butler, M. Di Ventra, S. Garaj, A. Hibbs, X. H. Huang, S. B. Jovanovich, P. S. Krstic, S. Lindsay, X. S. S. Ling, C. H. Mastrangelo, A. Meller, J. S. Oliver, Y. V. Pershin, J. M. Ramsey, R. Riehn, G. V. Soni, V. Tabard-Cossa, M. Wanunu, M. Wiggin and J. A. Schloss, Nat. Biotechnol., 2008, 26, 1146-1153.

106 D. H. Stoloff and M. Wanunu, Curr. Opin. Biotechnol., 2013, 24, 699-704.

107 Z. Chen, Y. Jiang, D. R. Dunphy, D. P. Adams, C. Hodges, N. Liu, N. Zhang, G. Xomeritakis, X. Jin, N. R. Aluru, S. J. Gaik, H. W. Hillhouse and C. J. Brinker, Nat. Mater., 2010, 9, 667-675.

108 G. A. Chansin, R. Mulero, J. Hong, M. J. Kim, A. J. DeMello and J. B. Edel, Nano Lett., 2007, 7, 2901-2906.

109 R. dela Torre, J. Larkin, A. Singer and A. Meller, Nanotechnology, 2012, 23, 385308.

110 W. Xu, J. G. Wang, M. F. Jacobsen, M. Mura, M. Yu, R. E. A. Kelly, Q. Q. Meng, E. Laegsgaard, I. Stensgaard, T. R. Linderoth, J. Kjems, L. N. Kantorovich, K. V. Gothelf and F. Besenbacher, Angew. Chem., Int. Ed., 2010, 49, 9373-9377.

111 J. P. Hill, Y. Wakayama, M. Akada and K. Ariga, J. Phys. Chem. C, 2007, 111, 16174-16180.

112 D. W. Schmidtke, Z. R. Taylor, K. Patel, T. G. Spain, J. C. Keay, J. D. Jernigen, E. S. Sanchez, B. P. Grady and M. B. Johnson, Langmuir, 2009, 25, 10932-10938.
113 T. Pavkov-Keller, S. Howorka and W. Keller, in Progress in Molecular Biology and Translational Science: Molecular Assembly in Natural and Engineered Systems, ed. S. Howorka, Academic Press, London, 2011, vol. 103, pp. 73-130.

114 S. Howorka, Curr. Opin. Biotechnol., 2011, 22, 485-491.

115 D. Papapostolou and S. Howorka, Mol. BioSyst., 2009, 5, 723-732.

116 N. C. Seeman, Annu. Rev. Biochem., 2010, 79, 65-87.

117 F. A. Aldaye, A. L. Palmer and H. F. Sleiman, Science, 2008, 321, 1795-1799.

118 A. M. Hung, H. Noh and J. N. Cha, Nanoscale, 2010, 2, 25302537.

119 S. Howorka, Langmuir, 2013, 29, 7344-7353.

120 U. B. Sleytr, M. Sára, D. Pum, B. Schuster, P. Messner and C. Schäffer, in Biopolymers, ed. A. Steinbüchel and S. R. Fahnestock, Wiley-VCH, Weinheim, 2002, vol. 7, pp. 285338.

121 S. Scheuring, H. Stahlberg, M. Chami, C. Houssin, J. L. Rigaud and A. Engel, Mol. Microbiol., 2002, 44, 675684.

122 A. Ebner, F. Kienberger, C. Huber, A. S. M. Kamruzzahan, V. P. Pastushenko, J. Tang, G. Kada, H. J. Gruber, U. B. Sleytr, M. Sára and P. Hinterdorfer, ChemBioChem, 2006, 7, 588-591.

123 U. B. Sleytr, C. Huber, N. Ilk, D. Pum, B. Schuster and E. M. Egelseer, FEMS Microbiol. Lett., 2007, 267, 131-144.

124 U. B. Sleytr, E. Egelseer, D. Pum and B. Schuster, in Nanobiotechnology, ed. C. M. Niemeyer and C. A. Mirkin, Wiley-VCH, Weinheim, 2004, pp. 77-92.

125 E. Baranova, R. Fronzes, A. Garcia-Pino, N. Van Gerven, D. Papapostolou, G. Péhau-Arnaudet, E. Pardon, J. Steyaert, S. Howorka and H. Remaut, Nature, 2012, 487, 119-122.

126 T. Pavkov, E. M. Egelseer, M. Tesarz, D. I. Svergun, U. B. Sleytr and W. Keller, Structure, 2008, 16, 1226-1237.

127 R. P. Fagan, O. Qazi, D. I. Svergun, K. A. Brown and N. Fairweather, Mol. Microbiol., 2009, 71, 1308-1322.

128 D. N. Selmi, R. J. Adamson, H. Attrill, A. D. Goddard, R. J. Gilbert, A. Watts and A. J. Turberfield, Nano Lett., 2011, 11, 657-660.

129 E. Egelseer, I. Schocher, M. Sára and U. B. Sleytr, J. Bacteriol., 1995, 177, 1444-1451.

130 M. J. Ford, J. F. Nomellini and J. Smit, J. Bacteriol., 2007, 189, 2226-2237.

131 J. L. Tang, A. Ebner, H. Badelt-Lichtblau, C. Vollenkle, C. Rankl, B. Kraxberger, M. Leitner, L. Wildling, H. J. Gruber, U. B. Sleytr, N. Ilk and P. Hinterdorfer, Nano Lett., 2008, 8, 4312-4319.

132 J. Tang, A. Ebner, N. Ilk, H. Lichtblau, C. Huber, R. Zhu, D. Pum, M. Leitner, V. Pastushenko, H. J. Gruber, U. B. Sleytr and P. Hinterdorfer, Langmuir, 2008, 24, 1324-1329.

133 D. Moll, C. Huber, B. Schlegel, D. Pum, U. B. Sleytr and M. Sára, Proc. Natl. Acad. Sci. U. S. A., 2002, 99, 1464614651.

134 N. C. Seeman, J. Theor. Biol., 1982, 99, 237-247. 
135 K. Fujibayashi, R. Hariadi, S. H. Park, E. Winfree and S. Murata, Nano Lett., 2008, 8, 1791-1797.

136 S. H. Park, C. Pistol, S. J. Ahn, J. H. Reif, A. R. Lebeck, C. Dwyer and T. H. LaBean, Angew. Chem., Int. Ed., 2006, 43, 735-739.

137 W. Liu, H. Zhong, R. Wang and N. C. Seeman, Angew. Chem., Int. Ed., 2011, 50, 246-247.

138 J. Zheng, J. J. Birktoft, Y. Chen, T. Wang, R. Sha, P. E. Constantinou, S. L. Ginell, C. Mao and N. C. Seeman, Nature, 2009, 461, 74-77.

139 P. W. Rothemund, Nature, 2006, 440, 297-302.

140 B. Sacca and C. M. Niemeyer, Angew. Chem., Int. Ed., 2012, 51, 58-66.

141 T. Tørring, N. V. Voigt, J. Nangreave, H. Yan and K. V. Gothelf, Chem. Soc. Rev., 2011, 40, 5636-5646.

142 N. Stephanopoulos, M. H. Liu, G. J. Tong, Z. Li, Y. Liu, H. Yan and M. B. Francis, Nano Lett., 2010, 10, 27142720.

143 M. Endo, T. Sugita, Y. Katsuda, K. Hidaka and H. Sugiyama, Chem.-Eur. J., 2010, 16, 5362-5368.

144 Z. Zhao, Y. Liu and H. Yan, Nano Lett., 2011, 11, 2997-3002. 145 H. Dietz, S. M. Douglas and W. M. Shih, Science, 2009, 325, 725-730.

146 P. Yin, R. F. Hariadi, S. Sahu, H. M. Choi, S. H. Park, T. H. Labean and J. H. Reif, Science, 2008, 321, 824-826.

147 B. Wei, M. Dai and P. Yin, Nature, 2012, 485, 623-626.

148 Y. Ke, L. L. Ong, W. M. Shih and P. Yin, Science, 2012, 338, 1177-1183.

149 J. R. Burns, K. Göpfrich, J. W. Wood, V. V. Thacker, E. Stulz, U. F. Keyser and S. Howorka, Angew. Chem., Int. Ed., 2013, 52, 12069-12072.

150 J. Burns, E. Stulz and S. Howorka, Nano Lett., 2013, 13, 2351-2356.

151 J. D. Le, Y. Pinto, N. C. Seeman, K. Musier-Forsyth, T. A. Taton and R. A. Kiehl, Nano Lett., 2004, 4, 2343-2347.

152 J. P. Zhang, Y. Liu, Y. G. Ke and H. Yan, Nano Lett., 2006, 6, 248-251.

153 J. Sharma, Y. G. Ke, C. X. Lin, R. Chhabra, Q. B. Wang, J. Nangreave, Y. Liu and H. Yan, Angew. Chem., Int. Ed., 2008, 47, 5157-5159.

154 Y. Y. Pinto, J. D. Le, N. C. Seeman, K. Musier-Forsyth, T. A. Taton and R. A. Kiehl, Nano Lett., 2005, 5, 2399-2402.

155 J. W. Zheng, P. E. Constantinou, C. Micheel, A. P. Alivisatos, R. A. Kiehl and N. C. Seeman, Nano Lett., 2006, 6, 15021504.

156 S. H. Park, P. Yin, Y. Liu, J. H. Reif, T. H. LaBean and H. Yan, Nano Lett., 2005, 5, 729-733.

157 Y. He, Y. Tian, A. E. Ribbe and C. D. Mao, J. Am. Chem. Soc., 2006, 128, 12664-12665.

158 R. Chhabra, J. Sharma, Y. G. Ke, Y. Liu, S. Rinker, S. Lindsay and H. Yan, J. Am. Chem. Soc., 2007, 129, 10304-10305.
159 B. A. R. Williams, K. Lund, Y. Liu, H. Yan and J. C. Chaput, Angew. Chem., Int. Ed., 2007, 46, 3051-3054.

160 B. Sacca, R. Meyer, M. Erkelenz, K. Kiko, A. Arndt, H. Schroeder, K. S. Rabe and C. M. Niemeyer, Angew. Chem., Int. Ed., 2010, 49, 9378-9383.

161 S. Rinker, Y. G. Ke, Y. Liu, R. Chhabra and H. Yan, Nat. Nanotechnol., 2008, 3, 418-422.

162 S. Helmig, A. Rotaru, D. Arian, L. Kovbasyuk, J. Arnbjerg, P. R. Ogilby, J. Kjems, A. Mokhir, F. Besenbacher and K. V. Gothelf, ACS Nano, 2010, 4, 7475-7480.

163 I. H. Stein, C. Steinhauer and P. Tinnefeld, J. Am. Chem. Soc., 2011, 133, 4193-4195.

164 G. P. Acuna, F. M. Moller, P. Holzmeister, S. Beater, B. Lalkens and P. Tinnefeld, Science, 2012, 338, 506-510.

165 W. Q. Shen, H. Zhong, D. Neff and M. L. Norton, J. Am. Chem. Soc., 2009, 131, 6660-6661.

166 H. Z. Gu, J. Chao, S. J. Xiao and N. C. Seeman, Nat. Nanotechnol., 2009, 4, 245-248.

167 K. Lund, A. J. Manzo, N. Dabby, N. Michelotti, A. JohnsonBuck, J. Nangreave, S. Taylor, R. J. Pei, M. N. Stojanovic, N. G. Walter, E. Winfree and H. Yan, Nature, 2010, 465, 206-210.

168 S. F. Wickham, J. Bath, Y. Katsuda, M. Endo, K. Hidaka, H. Sugiyama and A. J. Turberfield, Nat. Nanotechnol., 2012, 7, 169-173.

169 S. F. Wickham, M. Endo, Y. Katsuda, K. Hidaka, J. Bath, H. Sugiyama and A. J. Turberfield, Nat. Nanotechnol., 2011, 6, 166-169.

170 D. H. Wilson, D. W. Hanlon, G. K. Provuncher, L. Chang, L. Song, P. P. Patel, E. P. Ferrell, H. Lepor, A. W. Partin, D. W. Chan, L. J. Sokoll, C. D. Cheli, R. P. Thiel, D. R. Fournier and D. C. Duffy, Clin. Chem., 2011, 57, 1712-1721.

171 D. M. Rissin, D. R. Fournier, T. Piech, C. W. Kan, T. G. Campbell, L. Song, L. Chang, A. J. Rivnak, P. P. Patel, G. K. Provuncher, E. P. Ferrell, S. C. Howes, B. A. Pink, K. A. Minnehan, D. H. Wilson and D. C. Duffy, Anal. Chem., 2011, 83, 2279-2285.

172 J. M. Emory, Z. Peng, B. Young, M. L. Hupert, A. Rousselet, D. Patterson, B. Ellison and S. A. Soper, Analyst, 2012, 137, 87-97.

173 W. J. Cho, Y. Kim and J. K. Kim, ACS Nano, 2012, 6, 249-255. 174 M. Greenfeld, D. S. Pavlichin, H. Mabuchi and D. Herschlag, PLoS One, 2012, 7, e30024.

175 R. J. Kershner, L. D. Bozano, C. M. Micheel, A. M. Hung, A. R. Fornof, J. N. Cha, C. T. Rettner, M. Bersani, J. Frommer, P. W. K. Rothemund and G. M. Wallraff, Nat. Nanotechnol., 2009, 4, 557-561.

176 A. M. Hung, C. M. Micheel, L. D. Bozano, L. W. Osterbur, G. M. Wallraff and J. N. Cha, Nat. Nanotechnol., 2010, 5, 121-126. 